\title{
A BIOÉTICA AMBIENTAL E ECOLOGIA PROFUNDA SÃO PARADIGMAS PARA SE PENSAR O SÉCULO XXI?
}

\section{ENVIRONMENTAL BIOETHICS AND DEEP ECOLOGY ARE PARADIGMS FOR THINK THE CENTURY XXI?}

\author{
Rodrigo Siqueira-Batista ${ }^{1,2}$, Giselle Rôças ${ }^{2}$, Andréia Patrícia Gomes ${ }^{1}$, Rosângela Minardi \\ Mitre Cotta ${ }^{3}$, Jorge Cardoso Messeder ${ }^{2}$ \\ ${ }^{1}$ Curso de Graduação em Medicina, Centro Universitário da Serra dos Órgãos (UNIFESO). \\ ${ }^{2}$ Programa de Pós-Graduação de Stricto Sensu em Ensino de Ciências, Centro Federal de Educação \\ Tecnológica de Química (CEFET de Química de Nilópolis) - Rua Lucio Tavares, 1045. Centro, Nilópolis. \\ Rio de Janeiro. Cep: 26530-060 \\ ${ }^{3}$ Departamento de Nutrição e Saúde, Universidade Federal de Viçosa (UFV).
}

\section{Resumo}

Frente a mudanças climáticas, graves impactos ambientais e um futuro incerto, a humanidade inaugura o século XXI percebendo que a sua relação com a natureza precisa se modificar. É com base nessa reflexão que o diálogo entre Bioética e Ecologia, começa a ser alinhavado, trazendo para o bojo dos debates aspectos que ultrapassam as fronteiras dos conhecimentos e saberes específicos dessas áreas, incorporando em seu discurso as temáticas relativas à crise social e econômica, enfrentadas na contemporaneidade. $\mathrm{O}$ presente manuscrito pretende provocar nos leitores o interesse em se aprofundarem nas conversações travadas entre Ecologia e Bioética; trata-se, outrossim, de uma primeira aproximação a qual, se espera, poderá contribuir para a construção de novos referenciais para se pensar as relações homem-natureza no século XXI.

Palavras-chave: Bioética, Ecologia, Ecologia profunda, Educação Ambiental.

\begin{abstract}
Facing the climatic changes, severe environmental impacts and an unpredictable future, the humanity arrives in century XXI noticing that its relation with nature needs to change. In order do to achieve this, a reflection based on the dialogue between ethics and ecology takes place. The barriers of the specific knowledge are exceeded, incorporating in its speech thematic relative to the social and economic crisis. This manuscript intends to provoke the interest in these conversations, contributing for the discussions about man-nature relationship on century XXI.
\end{abstract}

Keyword: Bioethics, Ecology, Deep Ecology, Environmental Education

\section{Introdução}

A ecologia é um dos saberes que tem contribuído consistentemente para os debates sociais, éticos, políticos e econômicos nas sociedades laicas e plurais contemporâneas (BOFF, 2002; SIQUEIRA-BATISTA et al., 2007), face aos diversos problemas ambientais que acometem o Planeta Terra nos dias atuais, podendo-se citar (1) o buraco na camada de ozônio, (2) as mudanças climáticas e o aquecimento global e 
(3) o agravamento das catástrofes naturais, entre outros. Em escalas variáveis, tais alterações do meio ambiente provocam distúrbios em diferentes regiões, possibilitando a emergência e a reemergência de inúmeras doenças, a perda de domícilio por parcelas das populações, a descaracterização de habitats naturais causando a extinção e/ou migração de espécies animais nativas, as alterações dos ciclos de chuvas com impactos econômicos na agropecuária, entre outros. Os desdobramentos da crise ambiental se entrelaçam, então, com os demais aspectos das crises social e econômica enfrentadas na contemporaneidade, estabelecendo-se um padrão de teia — resultado da interdependência entre tais fatores —, no qual as ações e reações repercutem nos diferentes níveis da sociedade (CAPRA, 2001).

O presente manuscrito pretende provocar o interesse acerca de possíveis interseções entre Bioética e Ecologia, contribuindo assim para a construção de novos referenciais para se pensar as relações homem-natureza no século XXI.

\section{Bioética ambiental e Ecologia Profunda}

O termo ecologia — do grego, óikos = morada; lógos = discurso; ou seja, estudo sobre a casa - foi criado pelo biólogo Ernst Haeckel, em 1866 (HAECKEL, 1870). Seu significado originário - ciência que investiga a inter-relação entre os seres vivos em um dado espaço geográfico (sua casa) — está intimamente relacionada às questões ambientais. Em 1870, Haeckel refinou a definição do termo proposto por ele, conferindo uma amplitude maior, ao considerar a ecologia como um

[...] corpo de conhecimentos referente à economia da natureza, a qual compreende o estudo de todas as inter-relações complexas denominadas por Darwin como as condições de luta pela existência (Haeckel, 1870, p. 12).

As condições mencionadas por Darwin (1859) para a sobrevivência das espécies estão relacionadas tanto aos aspectos bióticos (relações com outros seres vivos) quanto aos abióticos (relações com os elementos físico-químicos do ambiente). É a partir dessa associação de definições e entendimentos, que a concepção de ecologia proposta por Haeckel - e fundamentada nas idéias de Darwin — ganhou força no meio acadêmico, de modo que, no início do século $\mathrm{XX}$, alguns cientistas já se autodenominavam ecólogos. Outras definições foram propostas ao longo dos anos, sem grandes modificações, o que se pode perceber em uma das conceituações mais atuais, formulada por Ricklefs (2003), o qual considera a ecologia como o ramo da ciência que estuda o 
ambiente natural e as relações dos organismos entre si e com os seus arredores. Tal definição representa não só uma flexibilidade da terminologia, mas principalmente um avanço do ponto de vista das intercessões que podem ser observadas nos estudos ecológicos, as quais, hoje ultrapassam os aspectos unicamente ecológicos, alcançando as fronteiras de outros saberes, tais como os da Ética e da Bioética (BOFF, 2002).

Ao longo do século XX, a ecologia construiu um robusto corpo de conhecimentos, o qual tem permitido explicar o funcionamento dos ecossistemas e as dimensões das alterações antrópicas sobre o meio ambiente. Tal entendimento tem se tornado cada vez mais importante para as tomadas de decisão políticas e econômicas, buscando minimizar os impactos ambientais, as catástrofes naturais e os problemas de saúde pública que podem ser acarretados em função do uso desregrado do ambiente.* Ademais, os conhecimentos ecológicos e seus modelos são aplicados em diversas áreas do saber, ganhando status de importante referencial teórico para se pensar o mundo contemporâneo — em termos éticos, políticos, epistemológicos e econômicos —, como demarcado por Leonardo Boff:

[a ecologia de] um discurso regional como subcapítulo da biologia, passou a ser atualmente um discurso universal, quiçá o de maior força mobilizadora do futuro milênio (Boff, 2005, p. 23).

A ecologia, assim, tem sido empregada para discutir díspares aspectos relacionados à vida na Terra, no âmbito de uma concepção de integração dos seres vivos. Mais recentemente, desde a década de 1970, tem se desenvolvido uma nova concepção da disciplina, a Ecologia Profunda, proposta, em 1973, pelo filósofo norueguês Arne Naess (NAESS \& ROTHENBERG, 1990) - incluído na tradição de pensamento ecológico-filosófico de Henry Thoreau e de Aldo Leopold —, como alternativa ao modelo hegemônico (Quadro 1) de pensar o homem como centro da natureza (GOLDIM JR, 2005) Deste modo, para Capra:

[...] a ecologia profunda não separa seres humanos — ou qualquer outra coisa - do meio ambiente natural. Ela vê o mundo não como uma coleção de objetos isolados, mas como uma rede de fenômenos que são fundamentalmente interconectados e são interdependentes. A ecologia

* Uma apreciação das relações entre minimizar os impactos ambientais, as catástrofes naturais e os problemas de saúde pública pode ser encontrada em: (1) MINAYO, Maria Cecília de Souza; MIRANDA, Ary C. de. Saúde e Ambiente Saudável: estreitando nós. Rio de Janeiro: Fiocruz, 2002.; e (2) ARAÚJO, Radamés Abrantes de Sousa. Aquecimento global e as conseqüências sobre as endemias transmitidas por vetores no Brasil. Trabalho de Conclusão de Curso (Especialização). São Paulo, Fundação Escola de Sociologia e Política de São Paulo, 2007. 
profunda reconhece o valor intrínseco de todos os seres vivos e concebe os seres humanos apenas como um fio particular na teia da vida (CAPRA, 2001).

Quadro 1. Comparação entre a visão de mundo hegemônica e a ecologia profunda.

\begin{tabular}{|c|c|}
\hline VISÃO DE MUNDO HEGEMÔNICA & ECOLOGIA PROFUNDA \\
\hline Domínio da Natureza & Harmonia com a Natureza \\
\hline $\begin{array}{c}\text { Ambiente natural como } \\
\text { recurso para os seres humanos }\end{array}$ & Toda a Natureza tem valor intrínseco \\
\hline $\begin{array}{c}\text { Seres humanos são superiores } \\
\text { aos demais seres vivos }\end{array}$ & Igualdade entre as diferentes espécies \\
\hline $\begin{array}{c}\text { Crescimento econômico e material como base } \\
\text { para o crescimento humano }\end{array}$ & $\begin{array}{c}\text { Objetivos materiais a serviço de objetivos } \\
\text { maiores de auto-realização }\end{array}$ \\
\hline $\begin{array}{c}\text { Crença em amplas reservas de recursos } \\
\text { Progresso e soluções baseados em alta } \\
\text { tecnologia }\end{array}$ & Planeta tem recursos limitados \\
\hline Consumismo & Tecnologia apropriada e ciência não dominante \\
\hline Comunidade nacional centralizada o necessário e reciclando \\
\hline
\end{tabular}

Fonte: GOLDIM JR (2005).

Sob esse novo olhar, surge a perspectiva de uma bioética ambiental, a qual traz impregnada em suas ações o cuidado de si em profunda integração ao cuidado do outro, no melhor espírito da interdependência:

[...] ocupar-nos de nós, cuidarmos de nós; não numa perspectiva de egoísmo ou de interesse individual, mas como aperfeiçoamento pessoal, superação dos apetites, dos desejos e paixões que possam dominar-nos. Ou seja, cuidar de si significa, antes de tudo, não ser escravo: dos outros, dos que nos governam, como de nós próprios, das nossas próprias paixões (LUNARDI et al., 2004).

Vale ressaltar que a própria bioética, desde suas origens, traz um discurso com marcante preocupação ecológica, o que aponta para uma intrínseca interseção entre as duas disciplinas. De fato, ao ser proposta pelo oncologista Van Rensslaer Potter, em 1970, a bioética foi caracterizada como uma nova ética científica capaz de dar respostas à deterioração das relações homem / natureza - entendendo-se que o primeiro comportava-se como um verdadeiro câncer para o planeta Terra - cujos objetivos principais seriam garantir a perpetuação da espécie humana e de sua qualidade de vida (POTTER, 1970). Neste sentido, utiliza a metáfora da ponte, delimitando a nova disciplina como uma ponte entre ciência biológica e filosofia (POTTER, 1970; POTTER, 1971) ou, em termos prigoginianos, como a "nova aliança" — diálogo entre as ciências da natureza e as humanidades (STENGERS \& PRIGOGINE, 1979). 
Ainda que, nestas décadas de desenvolvimento teórico, a disciplina tenha adquirido diferentes conotações - como, por exemplo, ética aplicada às ações pertinentes ao saber-fazer biomédico - nos últimos anos, sua vocação ecológica vem sendo recuperada - algo perceptível em recentes trabalhos (CARRICK, 2005; POTTER, 2000; SCHRAMM, 1997) — dirigindo-se às questões do planeta Terra em sua totalidade, o que pode ser entendido, conceitualmente, como um processo de legítima recomposição das dimensões ethos — bioética - e oikos - ecologia.

Seguindo tal proposição, deve-se incorporar, paulatinamente, os pressupostos destes diálogos possíveis — entre Bioética e Ecologia - nas ações cotidianas, movimento capaz de tornar os cidadãos mais conscientes, atuando de forma responsável com o ambiente e possibilitando que a Terra permaneça habitável e sustentável para as gerações presentes e futuras.

\section{Considerações Finais}

As crises social, sanitária e ambiental vivida atualmente, resultam em um quadro socioeconômico complicado, podendo-se destacar algumas situações emblemáticas na atualidade, tais como: diferenciação da renda entre os extremos, aumento da exclusão social, morbimortalidade por causas violentas, retorno/manutenção de doenças já conhecidas e com cura, "caotização" do espaço urbano, degradação dos recursos hídricos, poluição ambiental, especulação imobiliária com carência de saneamento básico e agravamento do problema do lixo contemporâneo (ARAUJO, 2007; CAPRA, 2006; GOMES et al., 2008; RÔÇAS et al., 2008), entre outros fenômenos socioambientais comumente debatidos nos diversos setores da sociedade. Nestes termos pode-se citar, como breve exemplo, a questão que envolve o destino dos resíduos sólidos, a qual causa problemas ambientais graves, em função da necessidade de criação de espaços para descarte, como os lixões e aterros controlados ou sanitários, podendo-se destacar três ordens de problemas: (1) a contaminação — do solo, de fontes hídricas próximas e de criadouro de animais - os quais são apenas algumas das consequências deletérias para a saúde; (2) a coleta seletiva — não implementada de forma adequada no Brasil - e o surgimento de catadores de lixo cadastrados pela COMLURB, os quais vivem a mercê da contaminação durantes as extensas horas de trabalho, além de estarem à margem da sociedade, dependendo dos seus "restos" para sobreviver; e (3) os aspectos atinentes à casa de cada cidadão, os quais consomem sem se preocupar com o destino do lixo gerado, sem perceber o passivo ambiental que está sendo gerado para as 
gerações futuras, sem se conscientizar da necessidade de repensar seus atos de consumo - com o objetivo final de comprar menos, exigindo menos recursos naturais durante o processo de produção —, mas principalmente, sem reavaliar seus hábitos e sua postura ambiental.

São cenários como esse que evocam a necessidade de uma discussão interdisciplinar, na qual os saberes das diversas áreas, debatidos de forma convergente, proporcionarão uma solução mais integral para os diversos problemas vividos nos dias atuais. É nessa vertente que a Bioética — ambiental — e a Ecologia — profunda — se aproximam como paradigmas para a reflexão no século XXI, na medida em que podem fornecer subsídios que corroborem para discussões pautadas não somente nos interesses individuais e imediatos, mas nos coletivos, em termos de presente e de futuro. Trata-se, pois, de construir novas relações com os seres que habitam o planeta, ao se compreender que a natureza tem um valor intrínseco, e não apenas instrumental.

\section{Referências}

Araújo, Radamés Abrantes de Sousa. Aquecimento global e as conseqüências sobre as endemias transmitidas por vetores no Brasil. Trabalho de Conclusão de Curso (Especialização). São Paulo, Fundação Escola de Sociologia e Política de São Paulo, 2007.

Boff, Leonardo. Ética da vida. Rio de Janeiro: Sextante, 2005.

Boff, Leonardo. Saber Cuidar. Ética do Humano - Compaixão pela Terra. $8^{\mathrm{a}}$ ed. Petrópolis: Vozes; 2002.

Capra, Fritjof. A teia da vida. uma nova compreensão científica dos sistemas vivos. 6.ed. São. Paulo: Cultrix, 2001.

Capra, Fritjof. Alfabetização ecológica. São. Paulo: Cultrix, 2006.

Carrick, Paul. The hidden costs of environmentally responsible health care. Perspect Biol Med 2005; 48(3):453-8.

Darwin, Charles. On the origin of the species by means of natural selection. London: John Murray, 1859.

Goldim Jr., José Roberto. Ecologia profunda. Consultado em http://www.ufrgs.br/bioetica/ecoprof.htm, setembro de 2007. 
Gomes, Andréia Patrícia; Santos, Marcos A.; Rôças, Giselle; Gonçalves, Marcelo L. C.; Siqueira-Batista, Rodrigo. Vida e morte na Amazônia: o desmatamento e a ecoepidemiologia da infecção por Trypanosoma cruzi como temática para a educação ambiental na formação de profissionais de saúde. In: Caderno de Resumos do Encontro Nacional de Ensino de Ciências da Saúde e do Ambiente. Niterói: UNIPLI, 2008. v. 1. p. 440-446.

Haeckel, Ernst. Natürliche schöpfungs-geschichte. $2^{\text {nd }}$ ed. Berlin: Georg Reimer, 1870.

Lunardi, Valéria Lerch; Lunardi Filho, Wilson Danilo; Silveira, Rosemary Silva; Soares, Narciso Vieira; Lipinski, Jussara Mendes. O cuidado de si como condição para o cuidado dos outros na prática de saúde. Rev. Latino-Am. Enfermagem, vol.12, no.6, p.933-939, Nov./Dec. 2004.

Minayo, Maria Cecília de Souza; Miranda, Ary C. de. Saúde e Ambiente Saudável: estreitando nós. Rio de Janeiro: Fiocruz, 2002.

Naess, Arne; Rothenberg, David. Ecology, community and lifestyle: outline of an ecosophy. Cambridge: Cambridge University Press, 1990

Potter, Van Rensslaer. Bioethics, science of survival. Biol Med 1970; 14:173-153.

Potter, Van Rensslaer. Bioethics: bridge to the future. Englewood Cliffs: Prentice Hall, 1971.

Potter, Van Rensslaer. Global bioethics with humility and responsibility. Biomedical Ethics 2000; 5(2):89-93.

Ricklefs, Robert. E. A economia da natureza. $5^{\text {a }}$ ed. Rio de Janeiro: Guanabara Koogan, 2003.

Rôças, Giselle; Gonzalez, Wânia; Sacramento, Patrícia. O despertar da responsabilidade socioambiental a partir da implantação da coleta seletiva em uma escola de educação tecnológica federal. In: Caderno de Resumos do Encontro Nacional de Ensino de Ciências da Saúde e do Ambiente. Niterói : UNIPLI, 2008. v. 1. p. 318-328.

Schramm, Fermin Roland. Niilismo tecnocientífico, holismo moral e a 'bioética global' de V. R. Potter. História Ciencias Saúde-Manguinhos, v. 4, n. 1, p. 95-115, 1997. 
Siqueira-Batista, Rodrigo; Rubião, Eduardo C. N.; Cotta, Rosângela M. M.; Pissinatti, Alcides; Soranz, Daniel R.; Pinto, Luiz F. S. Epidemiologia e ecologia. In: SiqueiraBatista, Rodrigo; Corrêa, Anderson D.; Gomes, Andrea Patricia; Geller, Mauro. Moléstia de Chagas. $2^{a}$ ed. Rio de Janeiro: Rubio, 2007. Páginas 147-168.

Stengers, Isabelle; Prigogine, Ilya. La nouvelle alliance: metamorphoses de la science. Paris: Gallimard, 1979. 